\title{
«Cada Casa da Criança que se abre, corresponde a uma enfermaria que se fecha». Gerar, criar e educar no Portugal do Estado Novo
}

\author{
("With every Nursery School that opens, an infirmary closes». \\ Raising and educating children in Portugal's New State)
}

António GOMES FERREIRA

Faculdade de Psicologia e de Ciências da Educação

Luís MOTA

Instituto Politécnico de Coimbra, Escola Superior de Educação

*Universidade de Coimbra (GRUPOEDE, CEIS20, UC)

RESUMO: A análise centra-se no programa das Casas da Criança enquadrado na obra social e educativa edificada pela ação, sucessiva, das Juntas Geral do Distrito de Coimbra, da Província da Beira Litoral e Distrital de Coimbra, lideradas por Fernando Bissaya Barreto, entre 1927 e 1974. Discute-se o programa pelo viés da inovação em educação enquanto introdução do novo e a reconfiguração das relações com o saber e o poder. Interpelamos um conjunto multivariado de fontes arquivísticas, e.g., processos de admissão às Casas da Criança, os livros de atas, plantas e alçados, fotografias e um conjunto de trabalhos elaborados por estagiárias. Das fontes publicadas destacam-se a imprensa escrita e algumas publicações contemporâneas dos acontecimentos. 0 corpus documental foi sujeito ao método crítico e à análise de conteúdo e recorreu-se à triangulação de fontes para uma leitura mais totalizante. Obteve-se uma compreensão complexa da realidade educacional, captando dimensões de inovação educativa e dos seus limites.

PALAVRAS-CHAVE: Inovação educativa; Casas da criança; Bissaya Barreto; Estado Novo; Educação de infância.

ABSTRACT: The analysis focuses on the Casas da Criança (Nursery School) program included in the social and educational work developed by the General Board of the District of Coimbra, the Board of the Province of Beira Litoral and the Board of the District of Coimbra, led by Fernando Bissaya Barreto, between 1927 and 1974. The program is discussed from the standpoint of pro-innovation bias in education in terms of the introduction of new ideas and the process of reshaping our relationship with knowledge and power. We address a multivariate set of archival sources, e.g. admission procedures to the Casas da Criança, minutes books, plans and elevations, photographs and a series of studies done by trainees. Noteworthy among 
the published sources are the printed media and some of the contemporary publications of the events. The documentary works were examined using the critical method and a content analysis. The triangulation of data sources was also used to obtain a more comprehensive reading. A complex understanding of the educational situation was obtained, with insight into the dimensions of educational innovation and its limits.

KEY-WORDS: Educational innovation; Casas da criança; Bissaya Barreto; Estado Novo; Early childhood education.

\section{Texto(s) e contexto(s)}

O propósito do presente artigo é dar nota de um programa que, situado entre a assistência e a educação, constituiu uma iniciativa inovadora porquanto, incorpora o novo. As Casas da Criança, e a sua programação, corporizam a modernidade, num tempo em que essa materialização traduz, e é percebida enquanto tal, inovação, no caso específico, inovação em educação. A educação é aqui observada pela forma de transmissão de uma dada cultura -valores, normas e regras, aptidões, estilo, tecnologia, saber-, um corpo de teias de significados ${ }^{1}$ que esteiam projetos societais, necessariamente, espacial e temporalmente datados, e de como na transmissão empodera os indivíduos ${ }^{2}$. Nesta perspetiva, a inovação em educação inscreve-se no processo histórico ${ }^{3}$ e transporta no seu bojo a reconfiguração das relações com o poder e o saber distanciando-se daqueloutras meramente técnicas.

O desenvolvimento da modernidade encerrando profundas alterações para as formações sociais -e.g., económicas, sociais, culturais- criou as condições para um novo olhar sobre as populações, em geral, e sobre os problemas sociais da infância ${ }^{4}$, em especial -e.g., crescimento e desenvolvimento da criança-, multiplicando-se as propostas e ações dirigidas às crianças ${ }^{5}$. A família, as instituições educativas e um corpo de saberes -saberpoder veiculador de interpretações e prescritor de normas educacionais-, mediaram a leitura da infância. Constituiu-se uma racionalidade sobre o criar e o educar da criança e um corpo de saberes sobre o trato e a condição de ser criança, fixando-se a infância como idade da vida e enraizando-se a imagem da criança como um outro ${ }^{6}$. No âmbito dos saberes, o reforço do saber-poder médico esteve na base da formação de um conjunto

\footnotetext{
${ }^{1}$ Clifford Geertz, A interpretação das culturas (Rio de Janeiro: Zahar Editores, 1978).

2 Jerome S. Bruner, Para uma teoria da educação (Lisboa: Relógio D’Água, 1999).

${ }^{3}$ Françoise Cros, L'innovation scolaire (Paris: INRP, 2001).

${ }^{4}$ António Gomes Ferreira, Gerar, criar, educar: a criança no Portugal do Antigo Regime (Coimbra: Quarteto, 2000).

${ }^{5}$ Luciano Faria Filho, A infância e sua educação. Materiais, práticas e representações [Portugal e Brasil], (Belo Horizonte: Autêntica, 2004).

${ }^{6}$ Cristina Rocha, Manuela Ferreira, Maria Emília Vilarinho, «Mundos sociais e culturais das crianças, ofícios da infância partilhados", en O Particular e o Global no Virar do Milénio. Cruzar Saberes em Educação. Actas do 5. ํ Congresso da Sociedade Portuguesa de Ciências da Educação, Org. Margarida Fernandes (Lisboa: Colibri, 2002), 499-508.
} 
de outros saberes especializados -e.g., higiene ${ }^{7}$ - que geraram um complexo de preceitos sobre o educar e cuidar das crianças, respaldados numa conceção de infância ${ }^{8}$, que abriram espaço à progressiva intervenção de peritos na definição de infância e das práticas educativas consideradas adequadas.

Este reforço do saber-poder médico e da afirmação de diferentes disciplinas médicas, nomeadamente, a higiene, que se propunha resolver múltiplos problemas sanitários $^{9}$, articulado com poderes políticos e sociais, traduziu-se na afirmação e desenvolvimento de programas de aprofundamento da higienização pública e privada do corpo, singular e social, imbuídos do dever cívico de cada um ser, e manter-se, saudável, por si e pela nação. ${ }^{10}$

Ambições enquadradas no programa de modernidade que Portugal procurou acompanhar, confrontado com um quadro de depauperada situação física, material, moral, educacional e cultural das suas classes laboriosas ${ }^{11}$. Questão social que, tal como a imprensa da época ia dando nota ${ }^{12}$, em finais do século XIX e na $1^{\text {a }}$ metade do século $X X$, era considerada uma ameaça à ordem moral e aos bons costumes da sociedade burguesa e que, mormente, a par da proteção materno-infantil, constituiu problemática longitudinal aos diferentes regimes políticos, sem prejuízo da equidistância na sua interpelação e da ótica de análise. As crianças, enquanto futuro de Portugal e, sobretudo, as mães, foram as especiais destinatárias das campanhas profiláticas de saúde pública, respaldadas na ciência e em saberes técnicos especializados, nomeadamente através da imprensa de educação e ensino cuja ação se estendeu a todo 0 século $X X^{13}$, visando reconfigurar as práticas sociais. ${ }^{14}$

Foi neste(s) contexto(s) de esforço de atualização da modernidade em Portugal compaginada com um quotidiano marcado pelos flagelos sociais -tuberculose, mortalidade

\footnotetext{
${ }^{7}$ António Gomes Ferreira, "Higiene e controlo médico da infância e da escola», Cadernos Cedes, 23 (2003): 9-24.

${ }^{8}$ Nikolas Rose, Governing the soul: the shaping of the private self, (London: Free Association Books, 1999).

9 Ana Leonor Pereira, João Rui Pita, «Público e Privado. História Ecológico-Institucional do Corpo. 0 caso português (1900-1950). Apresentação sumária de um projecto aprovado", Estudos do Século XX 5 (2005): 439453.

${ }^{10}$ Alison Bashford, Imperial Hygiene. A Critical History of Colonialism, Nationalism and Public Health, (New York: Palgrave MacMillan, 2004).

${ }^{11}$ Irene Vaquinhas, "A família, essa "pátria em miniatura»", en História da Vida Privada em Portugal. A Época Contemporânea, dir. José Mattoso (Lisboa: Círculo de Leitores/Temas e Debates, 2011), 118-151.

${ }^{12}$ Irene Vaquinhas, "O conceito de "decadência fisiológica da raça" e o desenvolvimento do desporto em Portugal (finais do século XIX/Princípios do século XX)", Revista de História das Ideias, 14 (1992): 365-388.

${ }^{13}$ Carla Isabel Vilhena, "A educação para a maternidade nas revistas de educação familiar no último meio século» (Tese de doutoramento, Universidade Nova de Lisboa, 2010); Luís Mota, Carla Vilhena, António Gomes Ferreira, "O Semanário "Educação Nacional»: inovação e educação de infância em Portugal (1927-1976)", en La Prensa Pedagógica de los Professores, ed. José María Hernández Díaz (Salamanca: Ediciones Universidad de Salamanca, 2018), 249-261.

${ }^{14}$ Irene Vaquinhas, "A família, essa «pátria em miniatura»», en História da Vida Privada em Portugal. A Época Contemporânea, dir. José Mattoso (Lisboa: Círculo de Leitores/Temas e Debates, 2011), 118-151.
} 
infantil e sífilis ${ }^{15}$ - que se moldou, entre 1928 e 1931, o core de uma obra assistencial na então província da Beira Litoral ${ }^{16}$, maiormente, a Obra de Proteção à Grávida e Defesa da Criança (OPGDC) que enquadra as Casas da Criança.

A perspetiva aqui adotada elaborou-se a partir de um conjunto multivariado de fontes, disponíveis no Arquivo da Universidade de Coimbra -arquivo distrital-, no Centro de Documentação Bissaya Barreto e no Arquivo da Escola Normal Social de Coimbra, no Instituto Miguel Torga. Da documentação compulsada avultam os processos de admissão às Casas da Criança, os livros de atas da Junta, as plantas e os alçados, fotografias dos edifícios e de atividades das crianças e um conjunto de trabalhos elaborados pelas alunas da Escola Normal Social. Das fontes publicadas destacam-se os discursos do Presidente da Junta da Beiral Litoral aquando da inauguração das Casas da Criança ${ }^{17}$, a imprensa escrita e algumas publicações contemporâneas dos acontecimentos. 0 corpus documental foi sujeito ao método crítico $^{18}$ e à análise de conteúdo ${ }^{19}$ e recorreu-se à triangulação de fontes para uma leitura mais totalizante ${ }^{20}$ possibilitando uma compreensão complexa desta realidade educacional no sentido de apreender as dimensões de inovação, enquanto introdução do novo, seja ao nível das conceções pedagógicas, quer no campo das práticas educativas.

\section{Agência e estrutura(s): da junta da província da Beira Litoral à Escola Normal Social}

Natural de Castanheira de Pera, distrito de Leiria, Fernando Baeta Bissaya-Barreto Rosa (1884-1974) nasceu num contexto local em significativo e acelerado processo de industrialização com base nos lanifícios e no seio de uma família burguesa, representativa de uma certa elite científica, política - engajada ao republicanismo -, e religiosa. Ingressa na Universidade de Coimbra em 1903, chegando a professor catedrático da Faculdade de Medicina no início da década de quarenta (1942-1956). Republicano, maçon - membro do Grande Oriente Lusitano (1911-1913) -, positivista perfilhando um evolucionismo científico, em 1911 enfileira no Partido Republicano Evolucionista, de António José de Almeida, cujo programa político enfatiza os problemas da educação, assistência, saúde e higiene ${ }^{21}$, evoluindo no sentido de um republicanismo conservador, em busca de paz para poder tra-

\footnotetext{
${ }^{15}$ Fernando Bissaya-Barreto Rosa «Medicina Social - necessidade e urgência da sua organização em Portugal», en I Congresso da União Nacional. Volume II (Lisboa: União Nacional, 1935), 136-142.

${ }^{16}$ Jorge Manuel Pais de Sousa, Bissaya Barreto. Ordem e Progresso (Coimbra: Livraria Minerva Editora, 1999).

${ }^{17}$ Fernando Bissaya-Barreto Rosa, Uma Obra Social realizada em Coimbra. Volume I (Coimbra: Coimbra Editora, 1970).

${ }^{18}$ Paul Saint-Georges, "Pesquisa e crítica das fontes de documentação nos domínios económico, social e político», en Práticas e métodos de investigação em ciências sociais, Luc Albarello, Françoise Digneffe, JeanPierre Hiernaux, Christian Maroy, Danielle Ruquoy, Pierre de Saint-Georges (Lisboa: Gradiva, 1997), 15-47.

${ }^{19}$ Laurence Bardin, Análise de Conteúdo (Lisboa: Edições 70, 2011).

$20 \mathrm{Jim}$ Paul, «Between-method triangulation in organizational diagnosis», International Journal of Organizational Diagnosis, 4 (1996): 135-153.

${ }^{21}$ António Henrique de Oliveira Marques, História da Primeira República Portuguesa. As estruturas de base (Lisboa: Iniciativas Editoriais, 1978); António Henrique de Oliveira Marques, Portugal - Da Monarquia para a República (Lisboa: Editorial Presença, 1991).
} 
balhar e de ordem para progredir que reclamava desde $1915^{22}$, desembocando na União Nacional, presidida por António de Oliveira Salazar.

Deputado à Assembleia Constituinte (1911), e na legislatura de 1912 a 1915, ficou ligado à consagração constitucional do direito à assistência pública, génese simbólica da edificação de um regime assistencial moderno ${ }^{23}$. Já em pleno Estado Novo seria procurador à Câmara Corporativa, nas legislaturas de 1961-1965 e 1965-1969, como representante das instituições privadas de assistência. Circunstâncias pessoais e geográfico-eleitorais, a par do seu organicismo, conduzem-no a priorizar a política local, tendo exercido durante 43 anos, até 1974, o cargo de presidente, sucessivamente, da Junta Geral do Distrito, da Junta da Província da Beira Litoral e, finalmente, da Junta Distrital de Coimbra. Neste período desenvolveu, paralelamente, uma intensa atividade empresarial integrando o conselho de administração de grandes empresas - e.g., Sociedade Central de Cervejas de Coimbra ou a Fábrica de Porcelanas Vista Alegree ${ }^{24}$. Em 1958, criou uma fundação, com o seu nome, como instituição particular de assistência e de utilidade pública ${ }^{25}$.

A Junta, inicialmente órgão de administração regional do território e depois com estatuto de autarquia ${ }^{26}$, alternando o campo de intervenção no plano distrital -até 1936 e depois a partir de $1959^{27}$ - ou provincial, constituiu o locus da ação de Bissaya-Barreto. As Juntas Provinciais -Bissaya-Barreto presidiu à Junta da Província da Beira Litoral (JPBL) que integrava os distritos de Aveiro, Coimbra e Leiria- tinham atribuições de fomento e coordenação económica, de cultura e de assistência, cabendo-lhes no âmbito desta última atribuição, a construção e manutenção, com orçamento próprio ou em parceria com o Estado, de hospitais, dispensários centrais, preventórios e sanatórios ${ }^{28}$. A revisão da legislação encerrou a particularidade de abrir as realizações da Junta, para além do Estado, à comparticipação de iniciativas particulares, criando a possibilidade de participação da sociedade, e, simultaneamente, alargando o âmbito das iniciativas assistenciais. ${ }^{29}$

\footnotetext{
22 "Ao País", A Província (Coimbra), 22 de janeiro de 1915. Documento assinado por evolucionistas de Coimbra, entre os quais se podem destacar Fernando Bissaya-Barreto Rosa, Ângelo da Fonseca, A. Nogueira Lobo, Adriano da Cunha Lucas ou Augusto Joaquim Alves dos Santos.

${ }^{23}$ Irene Vaquinhas, "A família, essa "pátria em miniatura»», en História da Vida Privada em Portugal. A Época Contemporânea, dir. José Mattoso (Lisboa: Círculo de Leitores/Temas e Debates, 2011), 118-151.

${ }^{24}$ Alcina Martins, Maria Rosa Tomé, «Bissaya Barreto e a política assistencial da Junta da Província da Beira Litoral', en Bissaya Barreto (1886-1974). Percorrer uma vida e uma obra, dir. José Pedro Paiva, Patrícia Namorado da Costa Viegas Nascimento (Coimbra: Arquivo da Universidade de Coimbra/Fundação Bissaya Barreto, 2013), 45-85.

${ }^{25}$ "Despacho de 17 de novembro", Diário de Governo, no. 277, Série III (Lisboa: Ministério da Educação Nacional), 26 de novembro de 1958.

${ }^{26}$ "Constituição de 1933», en As Constituições Portuguesas. De 1822 ao texto atual da Constituição, ed. Jorge Miranda (Lisboa: Livraria Petrony Editores, 2004), 185-224.

${ }^{27}$ «Decreto-Lei no. 42536", Diário do Governo, no. 223, Série I (Lisboa: Ministério da Educação Nacional), 28 de setembro de 1959

${ }^{28}$ Código Administrativo, (Lisboa: Empresa Jurídica Editora, 1937).

29 "Decreto-Lei no. 31095», Diário do Governo, no. 303, Série I. (Lisboa: Ministério da Educação Nacional), 31 de dezembro de 1940.
} 
É no seio da JPBL que é criada a OPGDC, que constituiu uma resposta à realidade social envolvente reconhecendo a necessidade de uma ação de instrução e educação higiénica, a começar pelas crianças a quem se podia criar hábitos estruturais e inconscientes que respeitassem os princípios da boa higiene. Nesse sentido viria a elaborar-se um programa de assistência infantil que consistiu num verdadeiro dispositivo socio-sanitário ${ }^{30}$, no sentido foucaultiano do termo, cujos estabelecimentos funcionavam como «peças, ligadas e inter-ligadas" em "perfeita eficiência», culminando o percurso quando "poderem ser entregues à Sociedade, armados e equipados com uma boa saúde e uma útil profissão, para vencerem na vida» ${ }^{31}$. Os documentos, constantes em arquivo, comprovam a materialidade das afirmações. ${ }^{32}$

Estava-se perante um conjunto de instituições com diferentes valências que, especificamente para cuidar e educar as crianças, exigiam recursos humanos especializados, e cuja atividade, de acordo com Bissaya-Barreto, deveria ser cometida às mulheres, funções que estas afinal já desenvolviam no quadro das organizações médico-sociais, seja criar e educar crianças ou criar, sustentar e amparar obras sociais ${ }^{33}$. Factos que levaram 0 presidente da JPBL e a sua equipa diretiva, a tomarem a iniciativa, e a desenvolverem as diligências, para criar uma escola que formasse e educasse "Puericultoras, capazes de assistência integral à criança». ${ }^{34}$

A Escola Normal Social seria criada em 1937, dois anos mais tarde do que o Instituto de Serviço Social, em Lisboa, tornando-se na segunda escola de serviço social em Portugal. A direção da Escola Normal Social (ENS), em Coimbra, esteve, de início e até ao segundo lustro da década de cinquenta, entregue a Constance Davon, uma das francesas da Província Portuguesa da Congregação Franciscanas Missionárias de Maria que criara a ENS. Grupo de religiosas que pela sua formação, qualificação e experiência no âmbito da assistência social, Bissaya Barreto e a JPBL trouxeram para Portugal a fim de dirigir a OPGDC. 0 objetivo prioritário para a sua criação era, naturalmente, responder à carência de pessoal técnico especializado para a ação a desenvolver no âmbito da OPGDC. Do conjunto da sua oferta educativa, destaque-se o curso de Assistente Social, com a duração de três anos e, em exclusivo, no período de 1937 a 1956, o curso de Enfermeiras Puericultoras Visitadoras da Infância (EPVI), com a duração de dois anos. As circunstâncias históricas determinaram que a sua formação compaginasse uma racionalidade técnica e científica, fundada na influência da escola social de Le Play, com uma perspetiva mais vincadamente ideológica com raízes no Estado Novo ${ }^{35}$. A sua formação, numa apreciação a partir da legislação, contemplava disciplinas do âmbito das ciências

\footnotetext{
${ }^{30}$ Ricardo Jerónimo Silva, "Arquitectura hospitalar e assistencial promovida por Bissaya Barreto» (Tese de doutoramento, Universidade de Coimbra, 2013), 395.

${ }^{31}$ Rosa, Uma Obra Social realizada em Coimbra. Volume I, 298.

${ }^{32}$ Martins, Tomé, «Bissaya Barreto e a política assistencial da Junta da Província da Beira Litoral», 45-85.

${ }^{33}$ Rosa «Medicina Social - necessidade e urgência da sua organização em Portugal», 136-142.

${ }^{34}$ Rosa, Uma Obra Social realizada em Coimbra. Volume I, 364.

${ }^{35}$ Francisco Branco, «tinerário das profissões sociais em Portugal, 1910-1962», Análise Social, 214, L (1) (2015): 44-72.
} 
sociais, das ciências da educação, da medicina, uma vertente jurídico-constitucional do Estado corporativo e a doutrina social da Igreja. Ao nível das ciências da educação e medicina, os conhecimentos de Pedagogia, Psicologia, Psiquiatria e da Psicopedagogia - com demonstrações concretas no Ninho dos Pequenitos e no Jardim-Escola Oliveira Salazar - integraram sempre a formação das EPVI. Evidencie-se essa preocupação com a preparação nos domínios do cuidar e educar da criança que lhes deveria permitir atuar em consonância com as propostas da Educação Nova em contraponto à pedagogia dita tradicional. ${ }^{36}$

\section{Um programa para as "crianças sem pão ou agasalho»}

O programa das Casas da Criança visava enfrentar o problema da criança portuguesa. O quadro pintava-se de forma crua, uma elevada taxa de mortalidade infantil, o completo abandono na idade pré-escolar - extinta a oferta do Estado em 1937 mas cuja concretização, até então, fora quase nula -, a mãe no mercado de trabalho face ao exíguo salário paterno, deixava os infantes sem vigilância, sem "quem as vista, quem as lave, quem oriente os seus receios, quem obste às suas loucas correrias pela rua, quem canalize e discipline a sua atividade! „37, sujeitos à imprevisibilidade das intempéries, à promiscuidade com os animais ou expostos à agressividade dos seus pares, ficavam à mercê de um destino que lhes minava o corpo e conspurcava a alma. ${ }^{38}$

Os objetivos do programa passavam por proteger e vigiar a saúde, atender às necessidades e educar as crianças a partir da 1a infância, resolvendo, desde logo, os problemas de abandono, possibilitando às mães aceder a um trabalho remunerado fora de casa $^{39}$, substituindo, com vantagem, de acordo com Bissaya Barreto, as atarefadas mães (e pais), janela de oportunidade para a intervenção de pessoal especializado, cientificamente preparado para cuidar e educar a criança $a^{40}$. Objetivava-se preparar a criança para ser homem amanhã transmitindo normas e regras para uma boa saúde e criar hábitos de higiene, cuidando da dimensão física, mas igualmente da intelectual. Prescrevia-se, nesse sentido, o acompanhamento da criança desde o nascimento, vigiando o seu desenvolvimento e a sua atividade quotidiana. É neste enquadramento que se compreende o caráter nuclear atribuído à educação e, na boa tradição do republicanismo, a crença na capacidade de a educação criar um novo homem. ${ }^{41}$

O programa das Casas da Criança não se esgotava na educação da criança. As crianças são consideradas "vítimas da falta de educação dos pais»"2. A literatura in-

\footnotetext{
${ }^{36}$ Rosa, Uma Obra Social realizada em Coimbra. Volume I

${ }^{37}$ José dos Santos Bessa, no Congresso Nacional de Ciências da População, em 1940, citado por Rosa, Uma Obra Social realizada em Coimbra. Volume I, 192.

${ }^{38}$ Rosa, Uma Obra Social realizada em Coimbra. Volume I, 258.

${ }^{39}$ Maria Doroteia Baeta de Oliveira, «Relatório de visitas de estudo» (Escola Normal Social, 1964-1965).

${ }^{40}$ Rosa, Uma Obra Social realizada em Coimbra. Volume I

${ }^{41}$ lbídem.

${ }^{42}$ Rosa, Uma Obra Social realizada em Coimbra. Volume I, 160-161.
} 
ternacional, bem como estudos promovidos na formação social portuguesa ${ }^{43}$, vem demonstrando que a intervenção de saberes-poder e de técnicos especializados, que acompanham a produção da Modernidade, determinou a necessidade de se ser educado para se ser mãe. A ideia está na génese e na essência do programa da JPBL, visível nas valências previstas para as próprias Casas da Criança, e.g. planeamento de um consultório de pediatria em cada Casa da Criança. A educação higiénica, a alimentação ou noções de puericultura constituíam ensinamentos que pretendiam despertar nas mães uma "consciência maternal» transformando a sua educação em "fator de maior valor e da maior segurança para a proteção da infância» ${ }^{44}$, tanto mais que encerrava, em si, um potencial disseminador do conhecimento e das práticas de higiene pela comunidade. ${ }^{45}$

O relevo conferido ao papel da educação não será propriamente novo, conquanto a diligência com o educar as mães, a elaboração de um programa especial para cuidar e educar as crianças, entre os 0 e os 7 anos, centrado nas práticas de higiene e de saúde, ao nível profilático, bem como com a criação de rotinas visando a sua disciplinarização desde o berço, não pode deixar de ser perspetivado como inovação. O novo capta-se nas práticas legitimadas pela ciência, saberes-poder, contribuindo para a produção da Modernidade, práticas essas que, por um lado, conferem, às famílias e às crianças, poder sobre as próprias vidas e destinos, por outro, traduzem uma intromissão e um claro controlo das suas vidas por parte do(s) poder(es). De igual modo, pela monumentalidade com que se concretiza, bem como pelo setor social específico da população a que se dirige não pode deixar de se considerar que encerra um caráter inovador.

Os destinatários e as destinatárias do programa eram meninos e meninas em idade pré-escolar que provinham das classes populares. Na verdade, as crianças que frequentavam as Casas da Criança eram, genericamente, filhos e filhas de trabalhadores rurais, oficinais ou operários com um quotidiano de dificuldades. Não admira que nos seus discursos, Bissaya Barreto, se socorra de adjetivos e expressões como "Os mais fracos", "criança pobre e desprotegida», «infância desvalida» ou "crianças sem pão ou agasalho" ${ }^{46}$. Caracterização que não deve fazer perder de vista, a diversidade e especificidade dentro do próprio programa e, de igual modo, as variações dentro da mesma instituição. Apreciação global que não opaciza a especificidade e, até, o inusitado, como foi o caso de uma família portuguesa, residente em Santiago de Compostela onde o progenitor, doutor em Filologia Clássica pela Universidade de Coimbra e ao tempo leitor de português naquela Universidade, que, aquando de férias em Arganil, decidiu colocar as duas filhas a frequentar a Casa da Criança D. Joaquina Barreto Rosa, mediante 0

\footnotetext{
${ }^{43}$ Carla Isabel Vilhena, «A educação para a maternidade nas revistas de educação familiar no último meio século»; Luís Mota, Carla Vilhena, António Gomes Ferreira, "O Semanário «Educação Nacional»: inovação e educação de infância em Portugal (1927-1976)».

${ }^{44}$ Rosa, Uma Obra Social realizada em Coimbra. Volume I, 150.

${ }^{45}$ Maria Armegilda Silva, "A protecção à infância através das "Casas da Criança» e a ação benéfica destas sobre o meio popular» (Escola Normal Social, s.d.).

${ }^{46}$ Rosa, Uma Obra Social realizada em Coimbra. Volume I, 158-160, 229, 236.
} 
pagamento de uma mensalidade, para ver se, na companhia do grupo, as meninas comeriam com mais apetite. ${ }^{47}$

Desconhece-se o desenvolvimento do processo e se, em última análise, a inserção de Maria da Saudade e de Maria Leonor, assim se chamavam as duas irmãs, num grupo da Casa da Criança de Arganil, as fez passar a comer com mais apetite. 0 episódio alerta para a natureza heterogénea de público e dos seus objetivos ao frequentarem uma das Casas da Criança, facto que convoca para a compreensão das diferenças entre as próprias Casas da Criança. Pelo edifício, de raiz -obedecendo ao projeto tipo, ou não- ou adaptado, sem esquecer a sua localização, ou pelos destinatários -e.g., idade cronológica, origens socioeconómicas e/ou culturais- e suas motivações, as Casas da Criança enquanto instituições de educação de infância conservavam um significativo grau de diferenciação que configura marca de cultura própria já que, se eram veículos de transmissão de cultura, nem por isso deixavam de ser produtoras de culturas. Constituíam como que realidade(s) dentro de outra(s) realidade(s), concitadas, à escala nacional (e internacional), a uma norma política e a uma estrutura educativa, atualizando-se na relação dialética entre a liberdade e autonomia dos seus atores, na fidelidade aos seus objetivos, a norma e a estrutura, configurando um espaço de emergência de infidelidades normativas e de construções identitárias. ${ }^{48}$

O mesmo episódio convida a uma outra abordagem que se prende com a importância, e o peso, das condições materiais no quotidiano das instituições e como estas chancelam as suas práticas. Muito provavelmente, isto porque não foi possível, de todo, aquilatar da situação, a mensalidade paga pela família das duas irmãs, teria significado no orçamento da Casa da Criança D. Joaquina Barreto Rosa. Facto que nos remete para o orçamento da OPGDC e, por extensão, das Casas da Criança. As Juntas -e.g., JPBL-, recebiam do Estado « $2 \%$ sobre as coletas das contribuições predial e industrial e do imposto profissional liquidados para 0 Estado, na área da respetiva jurisdição " ${ }^{49}$ pelo que a sua atuação de fomento, nomeadamente assistencial, esteve sempre subordinada à vontade do governo $0^{50}$. A inscrição anual de subsídios, para os planos de ação, no orçamento de Estado, quando aprovados, permitia aumentar o valor do orçamento. Para além desta, o recurso a financiamento de organizações públicas e privadas consti-

\footnotetext{
${ }^{47}$ Resumo da Ficha Familiar no. 31, Casa da Criança D. Joaquina Barreto Rosa (Arganil), 3 de julho de 1950, Arquivo da Universidade de Coimbra - Arquivo Distrital, caixa «Processos de admissão de Internados a cargo da Junta da Província da Beira Litoral 1922-1957».

${ }^{48}$ Licínio Lima, A Escola como Organização e a Participação Escolar: um estudo da escola secundária em Portugal (1974-1988) (Braga: Centro de Estudos em Educação e Psicologia/Instituto de Educação e Psicologia/ Universidade do Minho, 1998); Justino Magalhães, Tecendo Nexos: história das instituições educativas (Bragança Paulista: Editora Universitária São Francisco, 2004); José Luís Sanfelice, «História, Instituições Escolares e Gestores Educacionais", Revista HISTEDBR On-line, número especial, (2006): 20-27; Luís Mota, António Gomes Ferreira, "Uma instituição de formação de professores do ensino primário em Coimbra (1942-1974)", Educação e Realidade. 41 (Número especial) (2016): 1397-1418.

${ }^{49}$ Martins, Tomé, «Bissaya Barreto e a política assistencial da Junta da Província da Beira Litoral», 58.

${ }^{50}$ Fernando Catroga, "Geografia e política. A querela da divisão provincial na I Repíblica e no Estado Novo", en o poder local em tempo de globalização. Uma história e um futuro, coord. Fernando Taveira da Fonseca (Coimbra: Imprensa da Universidade, 2005), 171-242.
} 
tuía outra estratégia para dimensionar o orçamento anual. Foram, mormente, as «receitas adicionais ao Estado" que financiaram e possibilitaram a ação da JPBL, desde as matérias-primas aos subsídios anuais atribuídos pelas câmaras municipais às Casas da Criança, sem esquecer, de igual modo, as contribuições particulares ${ }^{51}$. 0 envolvimento das comunidades e das elites, em particular, foi uma realidade. Esta natureza compósita do orçamento, com a rúbrica de âmbito local a ter um peso não despiciendo, como se compreende, constitui mais uma condição para a diversidade entre as diferentes Casas da Criança. Os orçamentos da JPBL cumpriam o determinado pelo Código Administrativo, apresentavam-se sem déficits ou superavits, alardeando equilíbrio financeiro; contudo existiram restrições orçamentais e certas instituições estiveram sujeitas a vigilância e controlo orçamental, mais ou menos, rigoroso consoante as épocas e as condições com que se convivia ${ }^{52}$. As limitações orçamentais acarretavam, obviamente, constrições ao nível da gestão que emergem, nomeadamente, ao nível do pessoal. Definido um quadro de pessoal das Casas da Criança ${ }^{53}$, não deixamos de encontrar registos de falta de pessoal que, de acordo com os relatórios das alunas da Escola Normal Social que compulsámos, afetava não só o funcionamento global das Casas da Criança, mas também, muito sensivelmente, as práticas educativas, desde a postura das puericultoras à atividades das crianças ${ }^{54}$. Em função do exposto, tenha-se presente que, não poucas vezes, ideias generosas esbarram na dura realidade das condições materiais de existência, razão pela qual a presença de um discurso de inovação não significa, necessariamente, a sua concretização.

\section{Uma proposta pedagógica alicerçada na educação nova}

A atenção com as crianças e o rigor e a sistematicidade que o presidente da JPBL entregou à sua ação de proteção, assistência e educação da infância transparece tanto na cobertura territorial que a OPGDC alcançou na beira litoral, a par da vontade manifesta de edificar ou estabelecer Casas da Criança em cada concelho e, após alcançar esse desiderato, ir ao encontro das freguesias ${ }^{55}$, como na preocupação em criar um projeto tipo (figura 1) para aquelas instituições educativas. Decisão que traduzia, de algum modo, o cuidado dedicado a um processo que se queria descentralizado e cuja distribuição espacial pelo território se desejava homogénea, bem como pela ambição de padronização dessa oferta, visando preservar a filosofia de funcionamento ou o controlo dos serviços prestados. Curiosamente, ou talvez não, as próprias alterações ao projeto tipo estavam previstas e inseriam-se no quadro de respostas a necessidades específicas dos municípios, condições económicas, por exemplo, ou outras resultantes do terreno ou de espaço $0^{56}$. Perante a impossibilidade de edificar de raiz, as Casas da Criança eram instaladas em edifícios

\footnotetext{
${ }^{51}$ Martins, Tomé, «Bissaya Barreto e a política assistencial da Junta da Província da Beira Litoral»

52 Ibídem.

${ }^{53}$ Ibídem.

${ }^{54}$ Laura Rodrigues Pimenta, «Relatório de estágio» (Escola Normal Social,1943-1944); Maria Doroteia Baeta de Oliveira, «Relatório de visitas de estudo» (Escola Normal Social, 1964-1965).

${ }^{55}$ Rosa, Uma Obra Social realizada em Coimbra. Volume I, 177.

${ }^{56}$ Silva, «Arquitectura hospitalar e assistencial promovida por Bissaya Barreto»
} 
adquiridos e/ou adaptados para o efeito, numa opção que resultava da ponderação de fatores como os custos das obras e o tempo de resposta às necessidades.

Um olhar para o projeto tipo (figura 1), da autoria de Luiz Benavente (1937), religa-nos às valências das Casas da Criança. Desde logo, um consultório médico e a respetiva sala de espera. Recorde-se o que já foi destacado sobre o papel do consultório em termos de profilaxia e educação das mães. Não seria, por certo, igual em todas as Casas da Criança e, quiçá, nem terá funcionado, ao longo de três décadas, sempre da mesma maneira na mesma instituição mas, na Casa da Criança Rainha Santa Isabel, situada na margem esquerda do rio Mondego em Coimbra, na década de sessenta, funcionava duas vezes por semana, segunda e quarta-feira, e as consultas eram realizadas por uma equipa constituída por um médico, uma assistente social e uma enfermeira. Todo o serviço de consultório era assegurado pelo Instituto Maternal| ${ }^{57}$. Retomando o projeto tipo, existia um espaço para acolher as crianças dos 0 aos 3 anos - a creche - e uma sala para as atividades das crianças dos 3 aos 7 anos, o jardim de infância, servidas por uma sala para refeições e as instalações sanitárias. De topo, nas fachadas longitudinais, dois alpendres, um, de formato retangular, funcionando como extensão da creche, onde eram colocados os berços quando o tempo o permitia, aqueloutro, semicircular, em ligação com o jardim de infância, permitindo 0 acesso das crianças aos espaços ao ar livre (figura 2), em consonância com a proposta pedagógica que presidia às Casas da Criança, especialmente atenta às vivências e ao contacto com a natureza.

A trilogia higiene, alimentação, educação embasava a vida das crianças na Casa, acrescente-se, em qualquer das Casas. Já em 1935, Bissaya Barreto destacara a necessidade de criar a «religião da Higiene e da Profilaxia» para atuar, maiormente, sobre as crianças na procura da incorporação, da interiorização de práticas básicas de higien ${ }^{58}$, as Casas da Criança permitiram-lhe operacionalizar tais ideias. A higiene e a alimentação não cumpriam só a função de limpeza e conforto e de satisfação de uma necessidade básica, estas dimensões estabeleciam um ritmo. Representavam funções que se cumpriam de acordo com regras e com horários, mais ou menos rígidos, que conferiam uma cadência estruturante ao quotidiano das crianças gerando um ambiente geral de disciplina que facilitava e tornava mais eficaz a ação da puericultora e auxiliava as crianças a construírem e, progressivamente, exercerem o seu autocontrolo individual mas, igualmente, coletivo. Não admira por isso que no terceiro vértice da função das Casas da Criança, as práticas educativas se distribuam na rotina contribuindo para a criação de hábitos, dimensão essencial de qualquer programa educativo.

Perspetiva que nos ajuda a compreender a rotina destas instituições, especificamente, quando as crianças se encontram em regime de externato ou semi-internato. Nesta situação competia à puericultora receber as crianças, deixadas pelos pais quando se dirigiam para os locais de trabalho, observá-las, procedendo ao despiste de doenças,

\footnotetext{
${ }^{57}$ Maria da Ascensão Oliveira de Abreu Freire, «Relatório de visitas de estudo» (Escola Normal Social, 19641965), 7-8.

${ }^{58}$ Rosa «Medicina Social - necessidade e urgência da sua organização em Portugal», 136-142.
} 
realizar-Ihes a higiene - lavá-las, dar-lhes banho, caso fosse necessário -, vesti-las com roupa da casa e encaminhá-las para a sala ou para a creche, de acordo com a sua idade. Leve-se em linha de conta, desde logo, diferenças assinaláveis entre as Casas da Criança, dado que "a roupa da casa», de acordo com a localização, podia traduzirse numa muda de roupa com ou sem roupa interior ou, simplesmente, num bibe que se justapunha sobre a roupa que a criança trazia de casa. Diferença que não afetava a rotina que se estendia a todas as casas, dado que, independentemente do significado de "roupa da casa», as crianças, ao final do dia, eram despidas dessa roupa e eram entregues às mães com aqueloutra que tinham trazido vestida de manhã ${ }^{59}$, como nos explica Maria Doroteia Oliveira ${ }^{60}$, tendo registado no seu relatório que mudavam «a roupa às crianças, porque toda a roupa exterior das maiores é da Casa, assim como também a dos bebés, mesmo a interior, a estes dão-lhes também banho" "61. Chegava o momento em que a idade diferenciava as rotinas, os mais novos, depois de colocados na creche, ficavam todo dia sob vigilância precavendo alguma alteração do estado de saúde e, nessa eventualidade, a criança seria retirada «do dormitório para o isolamento» e «observada e medicada» enquanto, simultaneamente, a mãe seria avisada e convidada a levá-la para casa. ${ }^{62}$

Após a higiene pessoal a preocupação imediata era a alimentação, base fundamental do desenvolvimento, razão pela qual nas Casas da Criança se fornecia, logo à chegada e depois dos primeiros cuidados de higiene, um pequeno almoço, e, ao longo do dia, um almoço e uma merenda, refeições que, habitualmente, no seu conjunto tinham componentes alimentares como o pão, o leite, os legumes, a carne, o peixe, a fruta e os açúcares ${ }^{63}$. A alimentação, naturalmente, variaria de acordo com a Casa e com a época do ano e terá sido, mais ou menos rica, em ordem da disponibilidade financeira existente na Obra e da distribuição do orçamento, dado que não existia autonomia financeira de cada Casa, sendo, no entanto, dependentes de apoios e contributos locais. Aparentemente, numa das Casas da Criança de Coimbra ${ }^{64}$, em meados da década de sessenta, a descrição da alimentação coincide, lato senso, com aqueloutra realizada pelo presidente da JPBL.

No plano pedagógico, os discursos de Bissaya Barreto alinhavam o programa das Casas da Criança pelo diapasão da educação nova, manifestando a necessidade de uma educação que definia como construtiva, para fabricar homens preparados para o mundo em que vivem, de resto, o objetivo de toda e qualquer educação. Epiteta a pedagogia tradicional de livresca e da memória e, baseando-se na sua experiência pessoal, denuncia os

\footnotetext{
${ }^{59}$ Maria Augusta de Jesus Cardoso Duarte, «Relatório de estágio e de visitas de estudo» (Escola Normal Social, 1965-1966); Maria da Ascensão Oliveira de Abreu Freire, «Relatório de visitas de estudo» (Escola Normal Social, 1964-1965); Maria da Conceição de Oliveira Rendeiro, «Relatório de visitas de estudo» (Escola Normal Social, 1964-1965).

${ }^{60}$ Estagiária e aluna da Escola Normal Social.

${ }^{61}$ Maria Doroteia Baeta de Oliveira, «Relatório de visitas de estudo» (Escola Normal Social, 1964-1965), 8.

${ }^{62}$ Rosa, Uma Obra Social realizada em Coimbra. Volume I, 150.

${ }^{63}$ Ibídem, 173-174.

${ }^{64}$ Maria Augusta de Jesus Cardoso Duarte, «Relatório de estágio e de visitas de estudo» (Escola Normal Social, 1965-1966), 13.
} 
castigos, a violência, o domínio e a sujeição65. Convocando conceitos da Psicologia e da Sociologia e a autoridade de autores do «Movimento da Educação Nova» -e.g., Adolphe Ferrière ou Maria Montessori-e, à semelhança destes, inventaria um conjunto de razões que o conduziram à recusa do que identifica como escola tradicional: a imobilidade imposta à criança, o peso das matérias que sobrecarregam a criança, uma educação que só prepara para empregos públicos e uma formação à margem da vida e da sociedade ${ }^{66}$. 0 desenvolvimento de uma educação nova, nas Casas da Criança, necessitava que, através da observação, se conhecesse a criança, os gostos, os desejos, os caprichos e os impulsos, para se adequar a educação às circunstâncias e necessidades da época. ${ }^{67}$

A infância, na conceção de Bissaya Barreto, é a etapa da vida em que o organismo se encontra em pleno desenvolvimento e formação, período de maior andamento físico e mental. A criança é considerada um ser que, pela sua curiosidade, recetividade e sensibilidade, é de uma "plasticidade extrema» ${ }^{68}$, período ideal para 0 enraizamento de hábitos técnicos, para promover a evolução mental e acompanhar as experiências (iniciais) de sentimentos e emoções, conscientes de que «é à custa destas reações emocionais, forças mentais, da sua atitude social e orientação que resulta a formação da sua personalidade " ${ }^{69}$. Conceção da criança que se compagina com estoutra de capital-base da Nação ${ }^{70}$, em que se reconhece nas crianças que o valor, o prestígio e a força de uma nação dependem das crianças, pelo que elas devem merecer "os principais cuidados e atenções das Nações» "11. Um tom que nos remete, inevitavelmente, para os discursos do capital humano e para 0 ocedeísmo, pelo viés patriótico-nacionalista. Conceções que tornam inteligível a perceção da educação pré-escolar como essencial para a vida das crianças ${ }^{72} e$, naturalmente, aí se incluem as Casas da Criança.

Para esta(s) criança(s) reclamava-se, nas Casas da Criança, uma educação integral que fabricasse indivíduos completos, integrais e adaptados ou capazes de se adaptarem social, física, intelectual e moralmente à realidade, às condições de existência ${ }^{73}$. A educação integral visava, afinal, o cultivo do corpo, da inteligência, da moral e do caráter.

Para cumprir tal desiderato considerava-se fundamental que se respeitasse a liberdade e as necessidades fisiológicas da criança, de acordo com as orientações da doutrina de Maria Montessori ${ }^{74}$. Nesta perspetiva todo o momento e a ação são considerados educativos e espera-se que a criança escolha as tarefas que mais Ihe agradam e as cumpra, que leve até ao fim aquilo a que se propôs. A criança pode «ir e vir, fazer

\footnotetext{
${ }^{65}$ Rosa, Uma Obra Social realizada em Coimbra. Volume I, 183.

${ }^{66}$ Ibídem, 253-254.

${ }^{67}$ Ibídem, 183.

68 Ibídem, 210.

${ }^{69}$ Ibídem, 206.

70 lbídem, 160.

71 lbídem, 266.

72 Teresa Carmelita Pires Capelo, «Relatório de atividade geral» (Escola Normal Social, 1950-1951), 66

${ }^{73}$ Rosa, Uma Obra Social realizada em Coimbra. Volume I, 203.

74 Ibídem, 162.
} 
perguntas, escolher e mudar de lugar ${ }^{75}$. Estimulando a curiosidade e a imitação, à semelhança de Montessori, segundo o presidente da JPBL, desenvolver-se-ia a autoeducação na criança competindo à puericultora observar, guiar, ajudar e aconselhar, aqui "responder a perguntas» ${ }^{76}$, ali, estar disposta a "ouvir confidências» ${ }^{77}$, podendo ajudar a criança, mas "sem tomar nunca o seu lugar» ${ }^{78}$, enfim, a puericultora deve levar a sério e tratar «a criança como um ser dotado de razão, com personalidade própria, que ela respeita e procura compreender». ${ }^{79}$

No modelo pedagógico de Maria Montessori o meio ambiente, que inclui materiais e os exercícios pedagógicos, constitui uma componente-chave ${ }^{80}$. Nas Casas da Criança, o espaço e a sua organização conformam-se ao respeito pelo princípio de liberdade da criança. Edifício, o espaço envolvente, a organização e o mobiliário das salas são adequados às "características socioculturais " ${ }^{81}$ das crianças e obedecem a opções de caráter pedagógico. Nesse sentido, mesas, secretárias e armários baixos, compartimentos, cabides e lavatórios, louça sanitária, tudo está ao alcance da criança, sendo ela, por isso, «responsável pela ordem de todas as coisas, cada objeto tendo um lugar determinado».82

As salas respeitavam a dimensão considerada adequada, com paredes pintadas a cores suaves -evitando as excessivamente sombrias ou, ao invés, as demasiado vivas-e decoradas com reproduções de obras de arte ou «bonitas ilustrações»" ${ }^{83}$ acompanhavam um equipamento, no caso da valência de jardim de infância, ao serviço da execução livre de tarefas, com mesas individuais e de dois lugares, estoutras servindo para as crianças aprenderem a «trabalhar em conjunto» ${ }^{84}$. Uma grande mesa redonda central criava a oportunidade para que as crianças se organizassem em seu redor e desenvolvessem atividades mais coletivas e/ou colaborativas. Na parede ou assente num tripé, habitualmente, um quadro de ardósia para as crianças desenharem.

É assim, num ambiente alegre, admirável, excelso que se pretende ajudar o desenvolvimento da criança ${ }^{85}$. Na sua rotina diária as crianças têm oportunidade de cantar, dançar, desenhar ou executar trabalhos manuais ${ }^{86}$ e, sem perder de vista que o objetivo é educar e não instruir, bem como não esquecendo os ensinamentos de Pestalozzi, Froebel e Mon-

\footnotetext{
75 Ibídem, 241.

${ }^{76}$ Ibídem.

77 lbídem.

78 Ibídem.

79 Ibídem.

${ }^{80}$ António Gomes Ferreira, Luís Mota, Carla Vilhena, «Modelos curriculares para a Educação de Infância», em Caminhos de Educação de Infância em Portugal: políticas e perspetivas contemporâneas, ed. António Gomes Ferreira, Luís Mota, Carla Vilhena, (Santo Tirso: De Facto Editores, 2019) [No prelo].

${ }^{81}$ Silva, «Arquitectura hospitalar e assistencial promovida por Bissaya Barreto», 398.

${ }^{82}$ Rosa, Uma Obra Social realizada em Coimbra. Volume I, 241.

${ }^{83}$ Ibídem, 239

${ }^{84}$ Ibídem.

85 Silva, «Arquitectura hospitalar e assistencial promovida por Bissaya Barreto»

${ }^{86}$ Rosa, Uma Obra Social realizada em Coimbra. Volume I, 207.
} 
tessori sobre a fadiga da memória, através do exercício dos sentidos e com recurso à associação das ideias, também se cuida da sua educação intelectual. ${ }^{87}$

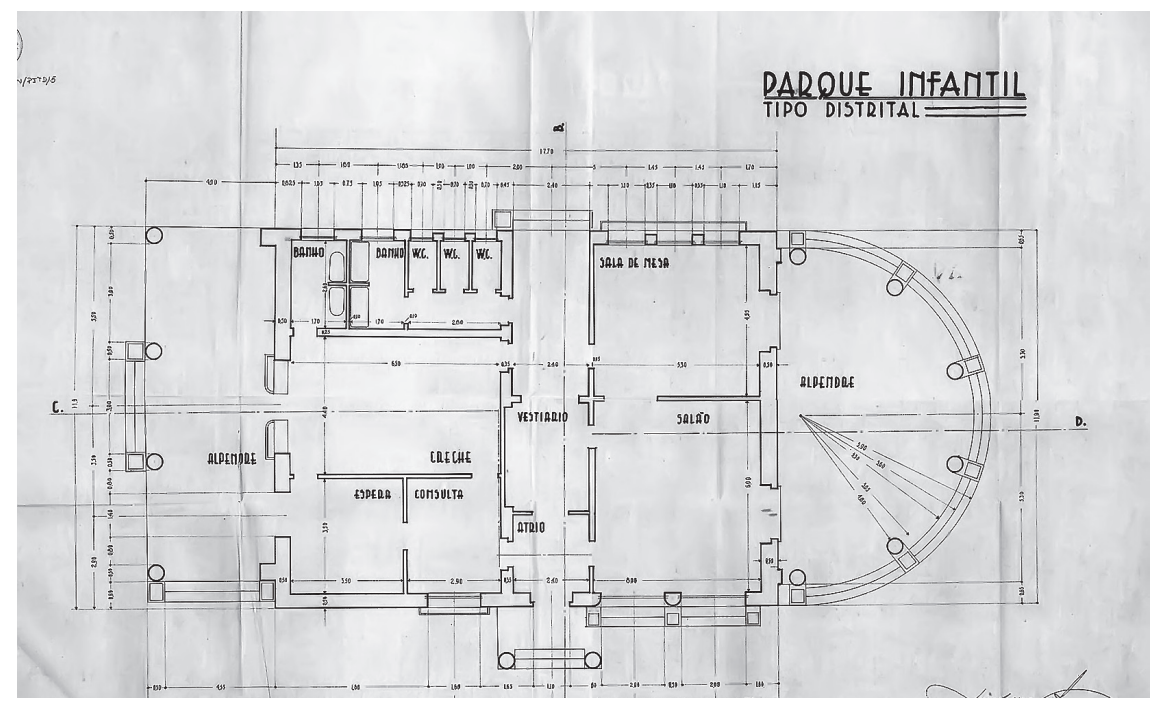

Figura 1. Planta parque

A articulação de todo 0 ambiente era uma realidade e como bem sublinhava o professor da Faculdade de Medicina coimbrã, para "salvar fisicamente e intelectualmente»"88 as crianças era necessário que se habituassem «a amar a vida livre ao ar livre, o sol, 0 campo e as flores do campo, a natureza simples" ${ }^{39}$. Uma pretensão que a rotina diária poderia ajudar a concretizar, mas, para isso, seria muito conveniente que os espaços contribuíssem para esse propósito. 0 aporte do edifício é logo fixado na planta tipo (figura 1) que denuncia esta ligação a uma vida ao ar livre com a sala a fluir para o espaço exterior ao seu alcance no alpendre semicircular - tão emblemático na arquitetura das Casas da Criança (figura 2). A abertura, de par em par, das portas da sala para 0 alpendre servia às crianças terem acesso aos jardins, bem como de recreio protegido da chuva, em ambos os casos proporcionando o acesso ao ar livre, puro e saudável. Atividades ao «ar livre, ao sol, em plena natureza» ${ }^{90}$ para uma vida vigorosa e saudável, daí a importância atribuída a um espaço enquadrador, o jardim e, quando foi possível, campos de jogos (figura 3) bem delimitados e adequados às brincadeiras de crianças do jardim-de-infância. Nos espaços cuidadosamente tratados, podiam as crianças «correr, saltar, fazer ginástica, brincar e pôr

\footnotetext{
87 Ibídem, 163.

${ }^{88}$ Ibídem, 207-208.

89 lbídem.

90 Ibídem, 173.
} 
em exercício a sua atividade lúdica»"91 atividades que eram consideradas «fonte de conhecimentos e de disciplina, fator de desenvolvimento do sistema nervoso, meio de correção dos instintos, estímulo contra a preguiça e a indolência»»92. A importância da vida ao ar livre e a liberdade concedida à criança, em tempo e espaço, para brincar e jogar, afinal, as crianças aprendem brincando. A atividade lúdica, considerada «necessidade imperiosa da criança»" ${ }^{93}$, era tida como um valioso instrumento de formação. Evocando Froebel, pensamento e método, reconhecia Bissaya Barreto, um valor educativo à brincadeira e aos brinquedos, salientando as importantes aprendizagens e a significativa experiência que estes Ihes proporcionavam. ${ }^{94}$

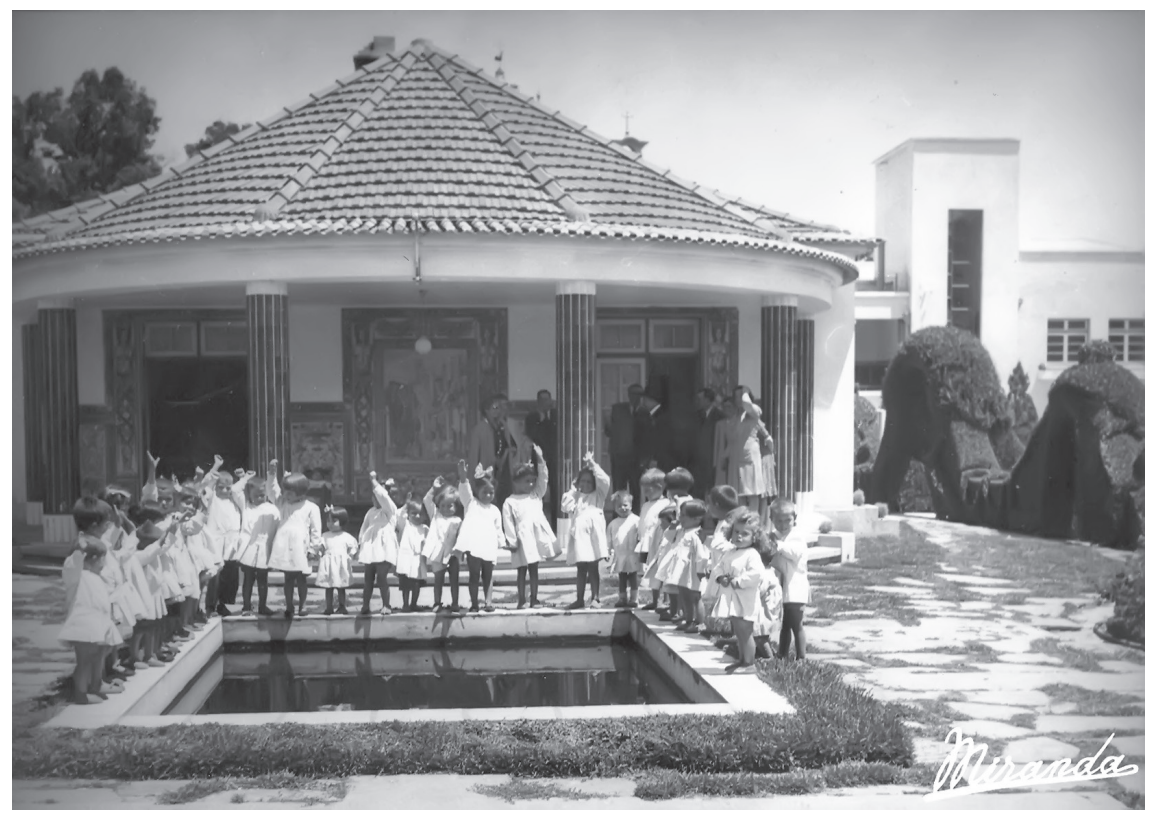

Figura 2. Acesso ao exterior.

A brincadeira promovia o convívio com as outras crianças constituindo uma outra dimensão educativa fundamental. $O$ entendimento ia no sentido de se considerar que as crianças se construíam e cresciam umas com as outras, única forma de se virem a assumir como adultos responsáveis e preparados para a vida social, desenvolvendo um autodomínio e uma autodisciplina dispensando condicionantes externos, simultaneamente com um espírito de solidariedade.

${ }^{1}$ Ibídem, 207-208

92 Ibídem.

${ }^{93}$ Ibídem, 172.

94 Ibídem. 
Em complemento com os campos de jogos existia um espaço ajardinado, de dimensões variáveis, com claros objetivos educativos (figura 4). 0 jardim, com «valência simbólico-funcional|» ${ }^{95}$, com uma estrutura geométrica, sugeria ordem, cuidado e fazia parte integrante do programa educativo das Casas da Criança. Enquanto espaço educativo, o jardim, como salientava Bissaya Barreto, oferecia a possibilidade de contacto com um ambiente atraente e o convívio e a familiaridade com o belo no dia-a-dia, contribuíam para o desenvolvimento do bom gosto. Apelava-se a «uma espécie de instinto da criança ${ }^{96}$, que, sentindo-se atraída pelo bem, gerasse um amor à beleza que, pela ação educativa, seria incorporado na sua personalidade. Proporcionava aprendizagens no contexto, como sublinhava o criador da Fundação Bissaya Barreto, «as ciências naturais estudam-se na cultura de jardinzinhos, na criação e cuidado de pequenos animais - nossos amigos". ${ }^{97}$

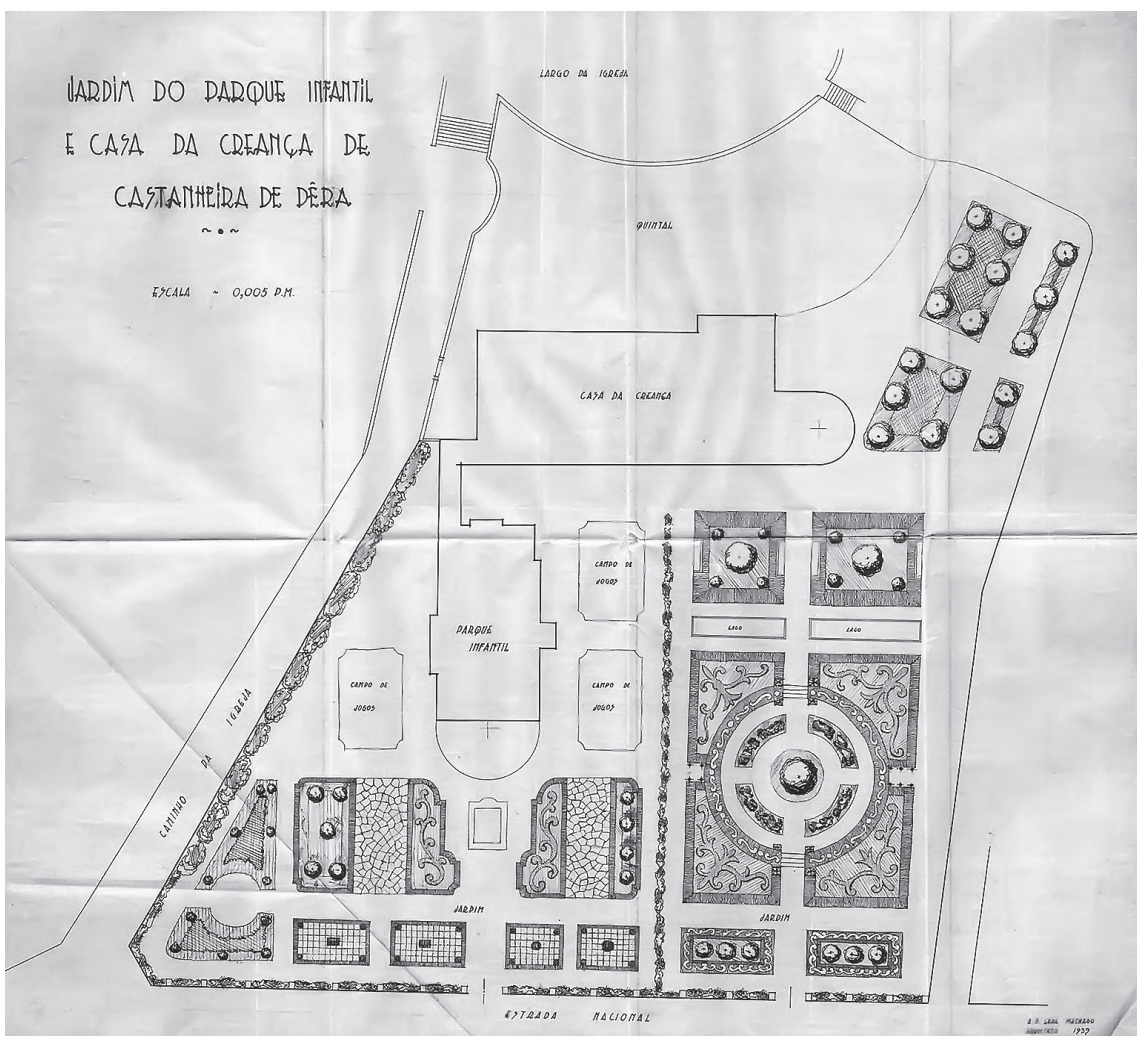

Figura 3. Parque Infantil de Castanheira Pera - jardim.

\footnotetext{
${ }^{95}$ Silva, «Arquitectura hospitalar e assistencial promovida por Bissaya Barreto», 434.

${ }_{96}$ Rosa, Uma Obra Social realizada em Coimbra. Volume I, 164.

${ }_{97}$ Ibídem, 246.
} 


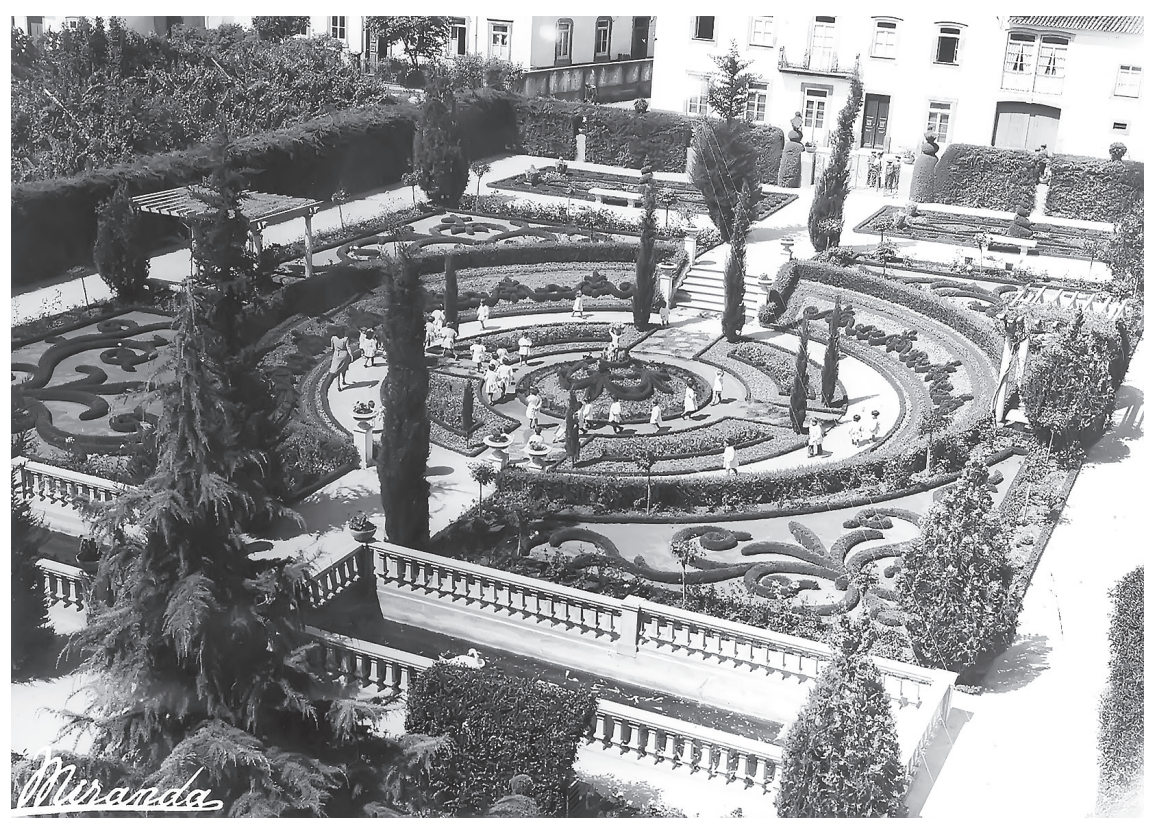

Figura 4. Jardins_cccp.

Considerava-se importante estimular "a imaginação, a curiosidade, o espírito de observação e de investigação" 98 bem como a importância de "compreender e trabalhar», daí o apelo às lições de coisas, consideradas a "base do desenvolvimento da criança» ${ }^{99}$. Como bem sabemos através das chamadas lições de coisas pugnava-se por um ensino prático e concreto, de acordo com o que se considerava serem as características da psicologia infantil. Procurava-se implementar um processo intuitivo, privilegiando os sentidos, despertando a atenção e a curiosidade, como forma de a criança tomar consciência dos fenómenos que a rodeavam. Para além das espécies vegetais, criavam-se animais para que as crianças os pudessem observar. Depois, com o apoio da puericultora, a criança deveria ver e tocar os animais. Guiada pela puericultora, diante do animal que servia de tema, a criança via e tocava, analisava características e podia estabelecer relações. Prosseguindo na linha das propostas pedagógicas sustentadas pelo positivismo evolucionista de Herbert Spencer, a criança caminhava do concreto para o abstrato, do simples para o complexo, do empírico para o racional e do indefinido para o definido. Era, para isso, fundamental tomar como ponto de partida o meio natural que as Casas da Criança proporcionavam às crianças e eram aqui mobilizados como suporte educativo fundamental.

\footnotetext{
98 Ibídem, 180.

99 Ibídem.
} 


\section{Notas finais}

Muito ao jeito de um conjunto de reflexões, procurou refletir-se, ao longo do artigo, sobre a problemática na inovação em educação, ou inovação educativa, a partir de um olhar sobre o programa das Casas da Criança no âmbito de uma obra social centrada em Coimbra com visão panorâmica para o distrito conimbricense ou para os distritos de Aveiro, Coimbra e Leiria, consoante o momento histórico. As reflexões aqui avançadas distribuem-se pela natureza do próprio programa, os seus propósitos e os seus destinatários, o ambiente e os edifícios onde se concretizou o programa, o modelo de financiamento do programa e, finalmente, o que podemos identificar como questões práticas de operacionalização, incluindo a dimensão pedagógica.

Assume-se, no presente estudo, que se entende por inovação em educação, a introdução do novo compaginado com a emergência de uma nova relação com o saber e o poder. Na realidade, no tempo que medeia entre o último lustro da década de vinte e meados da década de setenta do século passado, a inovação atualiza-se na Modernidade. $O$ novo olhar sobre a criança, a par das renovadas preocupações com o gerar, criar e educar, que se encontra de igual modo na génese da atenção prestada à educação das mães, resulta da afirmação e construção da Modernidade. Filiando-se no higienismo e na busca de disseminação dos hábitos de higiene e de boa saúde, respaldadas em práticas legitimadas pela ciência, consubstancia inovação na justa medida em que se difundem conhecimentos novos e novas práticas, bem como a apropriação desses conhecimentos e a interiorização dessas novas práticas vão conferir às crianças, e às suas mães, poder sobre os seus destinos. Resulta, nesta leitura, inegável, que, simultaneamente, o dispositivo criado no contexto da JPBL, representa disciplinarização e controlo sobre a vida das famílias e das crianças, refletindo uma intrusão na vida familiar, mas também individual. Está-se, para todos os efeitos, perante o desenvolvimento de novas relações com o saber e o poder.

Os destinatários, seja pela faixa etária em que são enquadrados -idades de frequência da creche e do jardim de infância-, ou pelas origens sociais -e.g., os deserdados-, conferem um caráter inovador ao programa, facto acentuado, nomeadamente, por se estar perante um Estado que abandonou a oferta de educação pré-escolar e onde as condições materiais de existência colocavam ainda num horizonte, mais ou menos longínquo, preocupações de generalização educativa.

Um programa que investe em edifícios, construídos de raiz ou adaptados, «esplendorosos" e com espaços adjacentes cuidadosamente tratados, contruídos com rigor e ordem, norteados pelos contributos da novel ciência e integrados com um conjunto de princípios pedagógicos, a par da preocupação para conferir um caráter sistemático ao processo de edificação -primeiro em cada concelho, depois as freguesias- e tendo como destinatários a "criança pobre e desprotegida», no contexto de um país em que o primeiro programa sistemático de construção de escolas remonta apenas a 1941 e cujo sistema educativo era, durante este período, transversalmente, socialmente seletivo, confere à ação da JPBL uma natureza inovadora. 
O modelo de financiamento encontrado pela JPBL, a forma como ultrapassou os $2 \%$ da contribuição predial e industrial e do imposto profissional, socorrendo-se de verbas consagradas no orçamento de Estado acrescidas do recurso a financiamento de organizações públicas e privadas, bem como recorrendo ao filantropismo, denotando a capacidade de envolver a comunidade, em geral, e as elites, em particular, no desenvolvimento do programa das Casas da Criança, representa algo de verdadeiramente novo para a época.

Para concluir, uma nota sobre a proposta pedagógica do programa das Casas da Criança que se inseria no quadro da educação nova, mobilizando contributos de Froebel e, muito especialmente, de Maria Montessori, num tempo em que progressivamente 0 modelo montessoriano se ia tornando prevalecente na formação social portuguesa ${ }^{100}$. Relatórios compulsados, de estagiárias da ENS, desocultaram dificuldades e contradições, em diferentes momentos e instituições, entre a enunciação do programa e as práticas educativas correspondentes. Tópico que convoca para dois pontos, o primeiro, a compreensão de que cada Casa da Criança é uma instituição específica, diferenciada das demais, com atores, adultos e crianças, contextos e circunstâncias distintos, exigindo uma apreciação per si. A realidade mostra-nos, efetivamente, que nem sempre, dependendo da época e da região, terá sido possível uma ação tão estruturada e claramente focada nos objetivos, pelo que muitas vezes ideias generosas esbarraram na dura realidade das condições materiais e simbólicas de existência, pelo que se pode avançar que se confirma a ideia de que a narrativa de um conjunto de ideias inovadoras não significa, necessariamente, a sua concretização.

\footnotetext{
100 António Gomes Ferreira, Luís Mota, Carla Vilhena, "Discursos sobre a emergência da educação da infância formal em Portugal (1880-1950)", Revista de História da Educação (Online). v. 23 (2019): e85647.
} 